\title{
Association of biomass fuel smoke with respiratory symptoms among children under 5 years of age in urban areas: results from Bangladesh Urban Health Survey, 2013
}


Wasimul Bari ${ }^{4}$ and Syed Shariful Islam ${ }^{1}$

\begin{abstract}
Background: Little is known regarding the effect of exposure to biomass fuel smoke inhalation on respiratory symptoms in the Bangladeshi population which is a major health hazard in most of the developing countries. This study aims to explore the association between respiratory symptoms and biomass fuel smoke exposure among children under 5 years of age.

Methods: Data were extracted from the Bangladesh Urban Health Survey conducted in 2013. A total of 10,575 mothers with at least one surviving children were selected. Respiratory symptoms among children under 5 years of age were considered as the primary outcome. Sequential multiple logistic regression models were used to observe the association between respiratory symptoms and biomass fuel smoke exposure adjusting the effect of residential factors and mother and child characteristics.

Results: Around $40 \%$ of the mothers exclusively used biomass fuel irrespective of the kitchen location and $54 \%$ of them were habituated in indoor cooking. The prevalence of respiratory symptoms of under-five children among inhouse and outdoor biomass fuel users was $23.0 \%$ and $21.9 \%$, respectively. Results of fitted multiple logistic regression models showed that the odds of having respiratory symptoms among children under 5 years of age were increased due to in-house biomass fuel use $[\mathrm{OR}=1.18 ; 95 \% \mathrm{Cl}, 1.04-1.36]$ compared with the non-biomass user. An increased risk of respiratory symptoms was also significantly associated with mother's birth complication $[\mathrm{OR}=1.51 ; 95 \% \mathrm{Cl}, 1.36-1.67]$, non-government organization (NGO) membership of mothers $[\mathrm{OR}=1.32 ; 95 \% \mathrm{Cl}$, 1.16-1.51], age of the child $(6-23 \mathrm{~m})[\mathrm{OR}=1.29 ; 95 \% \mathrm{Cl}, 1.10-1.52]$, and nutritional status (stunting) $[\mathrm{OR}=1.18 ; 95 \%$ Cl, 1.06-1.31].
\end{abstract}

Conclusion: This study found the use of in-house biomass fuel as a significant risk factor associated with respiratory symptoms of children under 5 years of age. More longitudinal studies should be designed to establish a causal relationship between HAP (household air pollution) and respiratory symptoms among children with more direct measures of HAP and clinical procedure.

Keywords: Biomass fuel smokes, Respiratory symptoms, Under-five children, Urban health, Bangladesh

\footnotetext{
* Correspondence: hasansbi88@gmail.com

'Department of Public Health and Informatics, Bangabandhu Sheikh Mujib

Medical University, Dhaka, Bangladesh

Full list of author information is available at the end of the article
}

(c) The Author(s). 2019 Open Access This article is distributed under the terms of the Creative Commons Attribution 4.0 International License (http://creativecommons.org/licenses/by/4.0/), which permits unrestricted use, distribution, and reproduction in any medium, provided you give appropriate credit to the original author(s) and the source, provide a link to the Creative Commons license, and indicate if changes were made. The Creative Commons Public Domain Dedication waiver (http://creativecommons.org/publicdomain/zero/1.0/) applies to the data made available in this article, unless otherwise stated. 


\section{Introduction}

Thermal energy is an essential item for cooking, lighting, and heating, etc. which are the basic needs of human beings. One of the main sources of this energy in developing countries is biomass fuel (i.e., wood, charcoal, animal dung, and agriculture residues) where people can hardly afford the cost of other types of expensive fuel (i.e., liquefied petroleum gas (LPG), electricity, biogas, ethanol gel, plant oils) [1]. Globally, $52 \%$ of the population counts on biomass fuel as the main source of energy for their daily cooking [2]. In developing countries, household use of biomass fuel covers almost $7 \%$ of primary energy demand [2] and approximately 3 billion people depend on solid fuel (biomass and coal) for their daily household work which is expected to increase until by 2030 [3]. Such use of biomass fuel for cooking and heating leads to incomplete combustion which is the main source of household air pollution (HAP). HAP is considered as a prime health concern as it has already crossed the standard tolerable limit [3]. Each year, there are approximately 3.8 million premature deaths from illness caused by HAP due to the inefficient use of solid fuels [4].

Women and children are at higher risk of exposure to the polluted air because of more household involvement than their counterparts [5]. According to the World Health Organization (WHO), 2.6\% of global health hazard is attributable to HAP from solid fuel which is preventable [5]. In low and middle-income countries (LMIC's), HAP is one of the leading causes of death from non-communicable diseases (NCDs) [4]. Among children under 5 years of age, almost $19 \%$ of deaths occur due to acute respiratory infection (ARI) and it is the second common cause of death in this age group [6]. Recent studies revealed that the use of solid fuels was significantly associated with neonatal mortality [7], infant mortality [7], under-five child mortality [8] and low birth weight (LBW) [7]. In Bangladesh, almost 73\% of households use biomass fuel as the main power source of cooking [9]. On the contrary, about one-fourth of the deaths among children under 5 years of age are associated with ARI, among which almost $43 \%$ are postneonatal (29 days-11 months) deaths [10].

Bangladesh is a developing country that is undergoing rapid urbanization [11]. The highest peak of the rural population was 106 million in 2016 which is now declining. In 2015, the urban population was 54 million which will be 81.4 million in 2029 [11] and Bangladesh will be an urban country by 2039 [12]. The urban population is so diverse and varied in terms of living and economic conditions and is characterized by large inequalities in health-related conditions.

Among the households in the urban area in Bangladesh, around $65 \%$ of people use biomass fuel as their main cooking fuel ingredients and almost $60 \%$ of households cook inside their house [12]. A study conducted on HAP revealed that a high concentration of air pollutants emitted from biomass fuel used in the kitchen [13]. In the winter season, the average concentration of carbon mono oxide $(\mathrm{CO})$, carbon dioxide $\left(\mathrm{CO}_{2}\right)$, dust particles, and $\mathrm{NO}_{2}$ during cooking was $7.6 \mathrm{ppm}, 662 \mathrm{ppm}, 1.051\left(\mathrm{mg} / \mathrm{m}^{3}\right)$, and $80.2\left(\mu \mathrm{g} / \mathrm{m}^{3}\right)$ respectively [13]. So HAP is becoming an important public health concern in this country. The existing literature has got very little information on ARI of children under 5 years of age who are exposed to biomass fuel smoke in urban Bangladesh, differentiating urban areas as city corporation slum and non-slum; and other urban areas. In general, the WHO recommended that the definition of ARI [14] is used to detect ARI cases. But in developing countries like Bangladesh, where clinical data on ARI are usually not available or very weak, the symptomatic definition of illness was widely used to provide a fairly good way of assessing symptoms of ARI in several population-based studies $[12,15,16]$. In this study, an attempt has been made to examine the association between the use of biomass fuel in daily cooking and the presence of respiratory symptoms of children under 5 years of age.

\section{Methods and materials}

\section{Study area}

This study was conducted in the urban areas of Bangladesh, which is divided into three groups: City Corporation slum, City Corporation non-slum, and other urban areas (district municipalities and large towns/Paurashavas with population over 45,000 habitants) [12].

\section{Study population and design}

In this cross-sectional study, data have been extracted from the Urban Health Survey (UHS) 2013 where a threestage cluster sampling technique was used. The detailed description of the survey methodology was published in the report [12]. In this survey, 450 Mohallas were randomly selected from City Corporation and another 184 from other urban areas. "Mahalla" is the lowest administrative division in the cities in Bangladesh [12]. A total of 53,790 households were selected for this survey from where 49,228 women were successfully interviewed. For this study, a total of 10,575 women age 15-49 years having at least one alive child under 5 years of age were selected for analysis. Multiple births of a mother were reshaped statistically so that a single observation was obtained for each multiple births. In analyzing data, it was assumed that observations are independent.

\section{Data management}

\section{Outcome variable}

The main variable of interest in this study was respiratory symptoms. Respiratory symptoms were defined as whether 
the children under 5 years of age had been suffering from cough during the last 2 weeks preceding the survey, shortness of breathing or rapid breathing, a problem in the chest including blocked, or running nose. Children who experienced at least one of the above-mentioned criteria were considered as having respiratory symptoms.

\section{Exposure variable}

The main exposure variable was the type of fuel used along with the place of cooking (non-biomass user, inhouse biomass user, and outdoor/separate house biomass user). Non-biomass fuel or material included electricity, liquefied petroleum gas, natural gas, and biogas; and biomass fuel included coal, lignite, charcoal, wood, straw/ shrubs/grass, agricultural crop, and animal dung [17].

\section{Other key variables}

Besides these exposures of biomass fuel uses, a range of potential confounders were selected based on previous studies demonstrating a significant impact on respiratory symptoms, which are participant's residential factors [13, 18], mother's characteristics [7, 19], and child characteristics $[18,19]$. Participants residential factors included area of the residence (city corporation: slum; city corporation: non-slum; and other urban areas) [12], migration status (migrated and non-migrated), toilet facility (improved and non-improved) [12], source of water (piped water, tube well, and others), floor materials (concrete/ cement and other materials), garbage disposal (improved and non-improved) [20]; mother's characteristics included mother's education (no formal education, primary, secondary, and above), age (less than 19, 20-29, 30, and above), birth complication of mothers, current employment status, number of children, exposure to media, Non-Government Organization (NGO) membership and place of handwashing (observed and non-observed) status [12]. Definitions of these variables were given in Additional file 1. The birth complication was defined if the mother experienced any of the following complications during delivery or after delivery. The complications are severe headache/blurred vision; convulsion/fits; high BP; severe bleeding; leaking membrane; mal-presentation; prolonged labour; retained placenta; high fever with smelly discharge, and edema [12]. NGO membership means if the mother belongs to any of the given organization which provides financial support with interest such as Grameen Bank, Bangladesh Rural Advancement Committee (BRAC), Bangladesh Rural Development Board (BRDB), Association for Social Advancement (ASA), and Proshika [12]. Child characteristics include the age of the child in months $(0-5,6-23,24-59)$, birth order $(1,2$, and $3+)$, gender, and nutritional [21] status (stunting) of the child. Details of these factors were given in the Bangladesh Urban Health Survey [12] and core questions on drinking water and sanitation for the household survey conducted by $\mathrm{WHO}$ and United Nations International Children's Emergency Fund (UNICEF) [20].

\section{Data analysis}

Descriptive statistics of outcome variables and exposure variables were presented in frequency and percentages. Participant's residential factors and characteristics of the mother and child were presented in tabular form with row percentage distribution and chi-square test was performed to examine the association between respiratory symptoms and each explanatory variable. Sequential multiple logistic regression modelling had been used to examine how the influence of biomass fuel on respiratory symptoms changes with the adjustment of different sets of covariates [22]. For this purpose, four logistic regression models had been considered, which were Model 1: Only use of biomass fuel; Model 2: Model $1+$ Residential factors; Model 3: Model $2+$ Mother's characteristics; and Model 4: Model 3 + Child's characteristic. The results of these models were expressed as adjusted odds ratios with $95 \%$ confidence interval (CI). Two-tailed Wald test was used to test whether socio-demographic factors were associated with respiratory symptoms at $1 \%$ and $5 \%$ level of significance. The goodness of fit of each model was tested using Hosmer and Lemeshow statistic [23, 24]. Data management and analysis were performed using STATA 14 (Stata Corp: College Station, TX, USA).

\section{Results}

Descriptive statistics of the respondent's residential factors, mother's characteristics, and child characteristics were given in Table 1 . About $40 \%$ of women exclusively used biomass fuel irrespective of kitchen location; and among the biomass fuel users, approximately $54 \%$ had a cooking place within the households. Table 2 demonstrated the prevalence of respiratory symptoms of children which were found higher for in-house biomass fuel users compared with non-biomass fuel users. This rate was $23.0 \%$ and $21.9 \%$ for in-house and outdoor biomass users respectively, whereas $19.1 \%$ for non-biomass users and the association was statistically significant $(p<0.01)$.

The prevalence of respiratory symptoms changed significantly $(p<0.05)$ with the area of residence and the highest was found in other urban areas (21.4\%) and the least in city corporation non-slum area (18.7\%). Children from households using non-improved toilet facilities $(22.8 \%)$ and tube well water $(21.6 \%)$ for their daily use had experienced the highest proportion of respiratory symptoms.

All mother characteristics and child characteristics were significantly associated with the presence of respiratory symptoms of children. Mothers who completed primary (21.3\%); and secondary and above (20.6\%) education level 
Table 1 Descriptive statistics of participant's residential factors, mother's characteristics, and child characteristics

\begin{tabular}{|c|c|}
\hline Exposure variables $(n)$ & Percentages \\
\hline \multicolumn{2}{|l|}{ Use of biomass fuel } \\
\hline Non-biomass user ( $n=6402$ ) & 60.5 \\
\hline In-house biomass user $(n=2235)$ & 21.1 \\
\hline Outdoor/separate house biomass user $(n=1938)$ & 18.3 \\
\hline \multicolumn{2}{|l|}{ Residential factors } \\
\hline \multicolumn{2}{|l|}{ Area of residence } \\
\hline City corporation: slum ( $n=4802)$ & 45.4 \\
\hline City corporation: non-slum ( $n=2433$ ) & 23.0 \\
\hline Other urban area $(n=3340)$ & 31.5 \\
\hline \multicolumn{2}{|l|}{ Migration status } \\
\hline Non-migrated $(n=6484)$ & 61.3 \\
\hline Migrated $(n=4091)$ & 38.6 \\
\hline \multicolumn{2}{|l|}{ Toilet facility } \\
\hline Not improved $(n=1605)$ & 15.1 \\
\hline Improved $(n=8970)$ & 84.8 \\
\hline \multicolumn{2}{|l|}{ Sources of water } \\
\hline Piped water $(n=5467)$ & 51.7 \\
\hline Tube well $(n=5034)$ & 47.6 \\
\hline Others $(n=74)$ & 0.7 \\
\hline \multicolumn{2}{|l|}{ Floor materials } \\
\hline Others (Earth/wood/tiles) $(n=3069)$ & 29.0 \\
\hline Concrete/cement $(n=7506)$ & 70.9 \\
\hline \multicolumn{2}{|l|}{ Garbage disposal } \\
\hline Not improved $(n=5404)$ & 51.1 \\
\hline Improved $(n=5171)$ & 48.9 \\
\hline \multicolumn{2}{|l|}{ Mother characteristics } \\
\hline \multicolumn{2}{|l|}{ Mothers education } \\
\hline No formal education $(n=1769)$ & 16.7 \\
\hline Primary $(n=3213)$ & 30.3 \\
\hline Secondary and above $(n=5593)$ & 52.8 \\
\hline \multicolumn{2}{|l|}{ Age of the mother (in years) } \\
\hline Less than $19(n=964)$ & 9.1 \\
\hline $20-29(n=7037)$ & 66.5 \\
\hline 30 and above $(n=2574)$ & 24.3 \\
\hline \multicolumn{2}{|l|}{ Birth complication of mother } \\
\hline No $(n=7215)$ & 68.2 \\
\hline Yes $(n=3360)$ & 31.7 \\
\hline \multicolumn{2}{|l|}{ Current working status of the mother } \\
\hline No $(n=8785)$ & 83.0 \\
\hline Yes $(n=1790)$ & 16.9 \\
\hline
\end{tabular}

Table 1 Descriptive statistics of participant's residential factors, mother's characteristics, and child characteristics (Continued)

\begin{tabular}{|c|c|}
\hline Exposure variables $(n)$ & Percentages \\
\hline \multicolumn{2}{|l|}{ Exposure to media } \\
\hline No exposure $(n=2551)$ & 24.1 \\
\hline At least one media exposed in everyday $(n=8024)$ & 75.8 \\
\hline \multicolumn{2}{|l|}{ Exposure to NGO } \\
\hline Not a member of $\mathrm{NGO}(n=8822)$ & 83.4 \\
\hline At least one NGO member $(n=1753)$ & 16.5 \\
\hline \multicolumn{2}{|l|}{ Place of hand washing } \\
\hline Not observed $(n=1165)$ & 11.0 \\
\hline Observed $(n=9410)$ & 88.9 \\
\hline \multicolumn{2}{|l|}{ Child characteristics } \\
\hline \multicolumn{2}{|l|}{ Age of the child (in months) } \\
\hline $0-5(n=1441)$ & 13.6 \\
\hline $6-23(n=4687)$ & 44.3 \\
\hline $24-59(n=4447)$ & 42.0 \\
\hline \multicolumn{2}{|l|}{ Birth order } \\
\hline $1(n=3639)$ & 34.3 \\
\hline $2(n=3774)$ & 35.6 \\
\hline $3+(n=3162)$ & 29.9 \\
\hline \multicolumn{2}{|l|}{ Gender of the children } \\
\hline Boy $(n=5290)$ & 50.0 \\
\hline Girl $(n=5285)$ & 49.9 \\
\hline \multicolumn{2}{|l|}{ Stunting } \\
\hline No $(n=5887)$ & 55.6 \\
\hline Yes $(n=3286)$ & 31.0 \\
\hline
\end{tabular}

had children with a higher proportion of respiratory symptoms than mothers having no formal education (18.0\%). Children of mothers having any complications at the time of delivery suffered more from respiratory symptoms than children of mothers with no complications ( $25.7 \%$ versus $18.0 \%$ ). The media played a positive role to reduce the respiratory symptoms of children. Children of mothers exposed to at least one media were less likely to develop respiratory symptoms than children of mothers not exposed to media. Similar results were found for children whose mothers were the member of NGO and having a handwashing place in their household. Children in the age group 6-23 months were at a higher risk than other age groups. The prevalence of respiratory symptoms was found higher $(24.1 \%)$ in the stunted child.

To find out the unadjusted and adjusted influence of biomass fuel use, four sequential multiple logistic regression models had been fitted and the results shown in Table 3. In the unadjusted model (Model 1), children from households using biomass fuel were significantly ( $p$ $<0.01)$ associated with respiratory symptoms. The odds ratio (OR) with 95\% CI for in-house and outdoor 
Table 2 Association between respiratory symptoms of the children and use of biomass fuel, residential factors, and mother and child characteristics

\begin{tabular}{|c|c|c|c|}
\hline \multirow[t]{2}{*}{ Explanatory variables $(n)$} & \multicolumn{3}{|c|}{ Respiratory symptoms } \\
\hline & $\begin{array}{l}\text { Absent } \\
(8414)\end{array}$ & $\begin{array}{l}\text { Present } \\
(2161)\end{array}$ & $p$ value \\
\hline \multicolumn{4}{|l|}{ Use of biomass fuel } \\
\hline Non-biomass user (6402) & 80.9 & 19.1 & \multirow[t]{3}{*}{$<0.001$} \\
\hline $\begin{array}{l}\text { In-house biomass user } \\
(2235)\end{array}$ & 77.0 & 23.0 & \\
\hline $\begin{array}{l}\text { Outdoor/separate house biomass } \\
\text { user (1938) }\end{array}$ & 78.1 & 21.9 & \\
\hline \multicolumn{4}{|l|}{ Residential factors } \\
\hline \multicolumn{4}{|l|}{ Area of residence } \\
\hline $\begin{array}{l}\text { City corporation: slum } \\
\text { (4802) }\end{array}$ & 79.4 & 20.6 & \multirow[t]{3}{*}{0.044} \\
\hline $\begin{array}{l}\text { City corporation: non-slum } \\
\text { (2433) }\end{array}$ & 81.3 & 18.7 & \\
\hline Other urban area (3340) & 78.6 & 21.4 & \\
\hline \multicolumn{4}{|l|}{ Migration status } \\
\hline Non-migrant (6484) & 80.1 & 19.9 & \multirow[t]{2}{*}{0.080} \\
\hline Migrant (4091) & 78.7 & 21.3 & \\
\hline \multicolumn{4}{|l|}{ Toilet facility } \\
\hline Not improved (1605) & 77.2 & 22.8 & \multirow[t]{2}{*}{0.011} \\
\hline Improved (8970) & 80.0 & 20.0 & \\
\hline \multicolumn{4}{|l|}{ Sources of water } \\
\hline Piped water (5467) & 80.6 & 19.4 & \multirow[t]{3}{*}{0.020} \\
\hline Tube well (5034) & 78.4 & 21.6 & \\
\hline Others (74) & 82.4 & 17.6 & \\
\hline \multicolumn{4}{|l|}{ Floor materials } \\
\hline $\begin{array}{l}\text { Others (Earth/wood/tiles) } \\
\text { (3069) }\end{array}$ & 79.2 & 20.8 & \multirow[t]{2}{*}{0.530} \\
\hline Concrete/cement (7506) & 79.7 & 20.3 & \\
\hline \multicolumn{4}{|l|}{ Garbage disposal } \\
\hline Not improved (5404) & 79.1 & 20.9 & \multirow[t]{2}{*}{0.220} \\
\hline Improved (5171) & 80.1 & 19.9 & \\
\hline \multicolumn{4}{|l|}{ Mother characteristics } \\
\hline \multicolumn{4}{|l|}{ Mothers education } \\
\hline No formal education (1769) & 81.9 & 18.0 & \multirow[t]{3}{*}{0.017} \\
\hline Primary (3213) & 78.6 & 21.3 & \\
\hline Secondary and above (5593) & 79.3 & 20.6 & \\
\hline \multicolumn{4}{|l|}{ Age of the mother (in years) } \\
\hline Less than 20 (964) & 77.1 & 22.9 & \multirow[t]{3}{*}{$<0.001$} \\
\hline $20-29(7037)$ & 79.4 & 20.6 & \\
\hline 30 and above (2574) & 80.9 & 19.1 & \\
\hline \multicolumn{4}{|l|}{ Birth complication of mother } \\
\hline No (7215) & 82.0 & 18.0 & \multirow[t]{2}{*}{$<0.001$} \\
\hline Yes (3360) & 74.3 & 25.7 & \\
\hline
\end{tabular}

Table 2 Association between respiratory symptoms of the children and use of biomass fuel, residential factors, and mother and child characteristics (Continued)

\begin{tabular}{|c|c|c|c|}
\hline \multirow[t]{2}{*}{ Explanatory variables $(n)$} & \multicolumn{3}{|c|}{ Respiratory symptoms } \\
\hline & $\begin{array}{l}\text { Absent } \\
(8414)\end{array}$ & $\begin{array}{l}\text { Present } \\
(2161)\end{array}$ & $p$ value \\
\hline \multicolumn{4}{|l|}{ Current working status of the mother } \\
\hline No (8785) & 79.0 & 21.0 & \multirow[t]{2}{*}{0.002} \\
\hline Yes (1790) & 82.4 & 17.6 & \\
\hline \multicolumn{4}{|l|}{ Exposure to media } \\
\hline No exposure (2551) & 78.4 & 21.6 & \multirow[t]{2}{*}{0.010} \\
\hline $\begin{array}{l}\text { At least one media exposed in } \\
\text { everyday (8024) }\end{array}$ & 79.9 & 20.1 & \\
\hline \multicolumn{4}{|l|}{ Exposure to NGO } \\
\hline Not a member of NGO (8822) & 80.5 & 19.5 & \multirow[t]{2}{*}{$<0.001$} \\
\hline At least one NGO member (1753) & 74.9 & 25.1 & \\
\hline \multicolumn{4}{|l|}{ Place of hand washing } \\
\hline Not observed (1165) & 76.9 & 23.1 & \multirow[t]{2}{*}{$<0.001$} \\
\hline Observed (9410) & 79.9 & 20.1 & \\
\hline \multicolumn{4}{|l|}{ Child characteristics } \\
\hline \multicolumn{4}{|l|}{ Age of the child (in months) } \\
\hline $0-5(1441)$ & 81.8 & 18.3 & \multirow[t]{3}{*}{$<0.001$} \\
\hline $6-23(4687)$ & 77.5 & 22.6 & \\
\hline $24-59(4447)$ & 81.1 & 18.9 & \\
\hline \multicolumn{4}{|l|}{ Birth order } \\
\hline $1(3639)$ & 77.1 & 22.9 & \multirow[t]{3}{*}{$<0.001$} \\
\hline $2(3774)$ & 80.7 & 19.3 & \\
\hline $3+(3162)$ & 81.1 & 18.9 & \\
\hline \multicolumn{4}{|l|}{ Gender of children } \\
\hline Boy (5290) & 78.8 & 21.3 & \multirow[t]{2}{*}{0.044} \\
\hline Girl (5285) & 80.4 & 19.6 & \\
\hline \multicolumn{4}{|l|}{ Stunting } \\
\hline No (5887) & 79.2 & 20.8 & \multirow[t]{2}{*}{$<0.001$} \\
\hline Yes (3286) & 75.9 & 24.1 & \\
\hline
\end{tabular}

biomass fuel users were $[\mathrm{OR}=1.27$; $95 \%$ CI: $(1.13-$ $1.42)]$ and $[\mathrm{OR}=1.19 ; 95 \% \mathrm{CI}:(1.05-1.34)]$ respectively.

Adjusted odds ratios were computed by considering all covariates in regression models that were found significantly associated with respiratory symptoms in bivariate analysis. It was observed from Model 2, Model 3, and Model 4 that though adjustment of potential confounders reduced the magnitude of the association between the use of biomass fuel and presence of respiratory symptoms of children under 5 years of age to some extent, the association remained still statistically significant $(p<0.01$ in Model 1 and Model 2; and $p<0.05$ in Model 3 and Model 4). After adjusting residential confounders, it was found that mothers who used in-house biomass fuel were $22 \%$ $[\mathrm{OR}=1.22$; $95 \%$ CI: $(1.07,1.39)]$ more likely to have 
Table 3 Effects of biomass fuel use, residential factors, and mother and child characteristics on respiratory symptoms based on sequential multiple logistic regression models

\begin{tabular}{|c|c|c|c|c|}
\hline \multirow[t]{2}{*}{ Explanatory variables } & Model 1 & Model 2 & Model 3 & Model 4 \\
\hline & UOR $[95 \% \mathrm{Cl}]$ & AOR $[95 \% \mathrm{Cl}]$ & AOR [95\% Cl] & AOR [95\% Cl] \\
\hline \multicolumn{5}{|l|}{ Use of biomass fuel } \\
\hline Non-biomass user & ref & ref & ref & ref \\
\hline In-house biomass user & $1.27[1.13-1.42]^{* * *}$ & $1.22[1.07-1.39]^{* * *}$ & $1.17[1.03-1.34]^{* *}$ & $1.18[1.04-1.36]^{* *}$ \\
\hline $\begin{array}{l}\text { Outdoor/separate house } \\
\text { biomass user }\end{array}$ & $1.19[1.05-1.34]^{* * *}$ & $1.13[0.99-1.29]$ & $1.12[0.97-1.28]$ & $1.13[0.97-1.30]$ \\
\hline \multicolumn{5}{|l|}{ Residential factors } \\
\hline \multicolumn{5}{|l|}{ Area of residence } \\
\hline City corporation: slum & & ref & ref & ref \\
\hline City corporation: non-slum & & $1.08[0.96-1.23]$ & $1.09[0.95-1.25]$ & 1.03 [0.90-1.19] \\
\hline Other urban area & & $1.06[0.92-1.23]$ & $1.04[0.89-1.20]$ & $0.97[0.83-1.13]$ \\
\hline \multicolumn{5}{|l|}{ Toilet facility } \\
\hline Not improved & & ref & ref & ref \\
\hline Improved & & $0.84[0.74-0.96]^{* * *}$ & $0.85[0.75-0.97]^{* *}$ & $0.85[0.74-0.97]^{* *}$ \\
\hline \multicolumn{5}{|l|}{ Sources of water } \\
\hline Piped water & & ref & ref & ref \\
\hline Tube well & & $1.05[0.95-1.18]$ & $1.02[0.92-1.15]$ & $1.02[0.91-1.15]$ \\
\hline Others & & $0.82[0.45-1.49]$ & $0.80[0.43-1.47]$ & $0.70[0.35-1.40]$ \\
\hline \multicolumn{5}{|l|}{ Mother characteristics } \\
\hline \multicolumn{5}{|l|}{ Mothers education } \\
\hline No formal education & & & ref & ref \\
\hline Primary & & & $1.22[1.04-1.41]^{* * *}$ & $1.21[1.03-1.42]^{* *}$ \\
\hline Secondary and above & & & $1.22[1.05-1.42]^{* * *}$ & $1.18[1.00-1.38]^{* *}$ \\
\hline \multicolumn{5}{|l|}{ Age of the mother (in years) } \\
\hline Less than 20 & & & ref & ref \\
\hline $20-29$ & & & $0.89[0.76-1.05]$ & $1.05[0.87-1.26]$ \\
\hline 30 and above & & & $0.83[0.69-1.00]$ & $1.00[0.79-1.25]$ \\
\hline \multicolumn{5}{|l|}{ Birth complication of mother } \\
\hline No & & & ref & ref \\
\hline Yes & & & $1.54[1.39-1.70]^{* * *}$ & $1.51[1.36-1.67]^{* * *}$ \\
\hline \multicolumn{5}{|l|}{ Current working status of the mother } \\
\hline No & & & ref & ref \\
\hline Yes & & & $0.81[0.71-0.93]^{* * *}$ & $0.88[0.76-1.02]$ \\
\hline \multicolumn{5}{|l|}{ Exposure to media } \\
\hline No exposure & & & ref & ref \\
\hline At least one media exposed in everyday & & & $0.92[0.81-1.03]$ & $0.90[0.79-1.02]$ \\
\hline \multicolumn{5}{|l|}{ Exposure to NGO } \\
\hline Not a member of $\mathrm{NGO}$ & & & ref & ref \\
\hline At least one NGO member & & & $1.32[1.16-1.49]^{* * *}$ & $1.32[1.16-1.51]^{* * *}$ \\
\hline \multicolumn{5}{|l|}{ Place of hand washing } \\
\hline Not observed & & & ref & ref \\
\hline Observed & & & $0.86[0.74-1.00]$ & $0.84[0.72-0.99]^{* *}$ \\
\hline
\end{tabular}


Table 3 Effects of biomass fuel use, residential factors, and mother and child characteristics on respiratory symptoms based on sequential multiple logistic regression models (Continued)

\begin{tabular}{|c|c|c|c|c|}
\hline \multirow[t]{2}{*}{ Explanatory variables } & Model 1 & Model 2 & Model 3 & Model 4 \\
\hline & UOR $[95 \% \mathrm{Cl}]$ & AOR $[95 \% \mathrm{Cl}]$ & AOR $[95 \% \mathrm{Cl}]$ & AOR $[95 \% \mathrm{Cl}]$ \\
\hline \multicolumn{5}{|l|}{ Child characteristics } \\
\hline \multicolumn{5}{|l|}{ Age of the child (in months) } \\
\hline $0-5$ & & & & ref \\
\hline $6-23$ & & & & $1.29[1.10-1.52]^{* * *}$ \\
\hline $24-59$ & & & & $1.05[0.89-1.24]$ \\
\hline \multicolumn{5}{|l|}{ Birth order } \\
\hline 1 & & & & ref \\
\hline 2 & & & & $0.83[0.73-0.94]^{* * *}$ \\
\hline $3+$ & & & & $0.80[0.68-0.94]^{* * *}$ \\
\hline \multicolumn{5}{|l|}{ Gender of children } \\
\hline Boy & & & & ref \\
\hline Girl & & & & $0.90[0.82-1.00]$ \\
\hline \multicolumn{5}{|l|}{ Stunting } \\
\hline No & & & & ref \\
\hline Yes & & & & $1.18[1.06-1.31]^{* * *}$ \\
\hline Goodness of fit of the models & $\begin{array}{l}\text { Hosmer-Lemeshow } \\
\text { chi2 (1) }\end{array}$ & $\begin{array}{l}\text { Hosmer-Lemeshow } \\
\text { chi2 (8) }\end{array}$ & $\begin{array}{l}\text { Hosmer-Lemeshow } \\
\text { chi2 (8) }\end{array}$ & $\begin{array}{l}\text { Hosmer-Lemeshow } \\
\text { chi2 (8) }\end{array}$ \\
\hline Test value ( $p$ value) & $0.00(1.00)$ & $13.84(0.08)$ & $4.71(0.78)$ & $7.22(0.51)$ \\
\hline
\end{tabular}

UOR unadjusted odds ratio, $A O R$ adjusted odds ratio, $\mathrm{Cl}$ confidence interval

$p<0.01$

${ }^{* *} p<0.05$

respiratory symptoms of children than non-biomass fuel users. This rate reduced to $17 \%[\mathrm{OR}=1.17 ; 95 \% \mathrm{CI}$ : $(1.03$, 1.34)] when both residential factors and mother characteristics were adjusted; and to $18 \%$ [OR $=1.18$; 95\% CI: (1.04, 1.36)], while child characteristics were taken into consideration along with confounders considered into the Model 4. The biomass fuel use in an outdoor/separate building for cooking purposes became an insignificant factor for respiratory symptoms when it was adjusted with residential factors.

It was evident from Model 2, Model 3, and Model 4 that improved toilet facility was found to be a significant protective factor of respiratory symptoms. Children under 5 years of age from households having improved toilet facilities were about $15 \%$ less likely to have respiratory symptoms compared with children from households not using improved toilet facilities. Observed place of handwashing was found as a protective factor for the development of respiratory symptoms of children under 5 years of age [OR = 0.84; 95\% CI: $(0.72,0.99), p<0.05]$ in Model 4 . The respiratory symptoms of children were higher among educated mothers. Odds ratio (OR) of having respiratory symptoms of children, whose mother completed primary, secondary, and above education, compared with non-educated mother was found to be $[\mathrm{OR}=1.22 ; 95 \% \mathrm{CI}:(1.04,1.41)]$ and $[\mathrm{OR}=1.22 ; 95 \% \mathrm{CI}:(1.05,1.42)]$ in Model 3 and $[\mathrm{OR}=1.21 ; 95 \% \mathrm{CI}:(1.03,1.42)]$ and $[\mathrm{OR}=1.18 ; 95 \% \mathrm{CI}$ : $(1.00,1.38)]$ in Model 4 respectively. If a mother faced any complication during pregnancy, the child was above $50 \%$ more likely $(p<0.01)$ to experience respiratory symptoms than a child whose mother did not face such complications. The percentages of respiratory symptom were higher among mothers who are the member of at least one NGO. If a mother was a member of NGO, her child was at least $32 \%(p<0.01)$ more likely to have respiratory symptoms compared with a child of non-NGO member mother.

In Model 4, the age of the children was found to be a significant determinant of the presence of respiratory symptoms. Children aged 6 to 23 months were 29\% ( $p<$ 0.01 ) more likely to have respiratory symptoms compared with other children. Odds ratio of having respiratory symptoms for the second child compared with the first child of parents was found [OR $=0.83$; 95\% CI: (0.73, $0.94)]$, whereas it was $[\mathrm{OR}=0.80 ; 95 \% \mathrm{CI}:(0.68,0.94)]$ if the birth order of the child is third or above. Malnutrition of children was found to be a significant $(p<0.01)$ risk factors for the presence of respiratory symptoms of children under 5 years of age. The malnourished (stunted) child was $18 \%$ more likely to be suffered from respiratory symptoms compared with healthy children. 


\section{Discussion}

Using sequential multiple logistic regression modelling to unveil the dynamics of interplay occurring between each of the explanatory variables, this study addressed gaps in the literature regarding using the type of cooking fuel, residential factors, mother and child characteristics, and their relationship with children's respiratory symptoms in urban areas in Bangladesh.

In this study, we found a high prevalence $(23.0 \%)$ of respiratory symptoms of under-five children of women who used in-house biomass fuel compared with nonbiomass fuel users (19.1\%). After adjusting all co-factors in the regression model, it revealed that respiratory symptoms were significantly associated with in-house biomass fuel use. The findings of this study are similar to the results of previous studies conducted in different countries. In Nigeria, the odds of having ARI symptoms among children under 5 years of age were increased $(\mathrm{OR}=2.30$, CI: 1.26-4.20) among in-house biomass fuel users compared with kerosene/charcoal users at an outdoor or separate place [18]. Households using solid fuel was 1.78 (CI: $1.05-2.99)$ times more likely to suffer from lower respiratory tract infections (LRTI) than the households using other fuel in India [19]. Children suffering from ARI was 1.79 (CI: 1.02-2.14) times higher among solid fuel users in Nepal [25]. In Bangladesh, nationwide population-based study data revealed that in-house solid fuel use increases the risk of ARI (1.18; CI: 1.08-1.33) symptoms among children under 5 years of age [7]. Another study conducted in the urban slum of Dhaka, Bangladesh, showed that respiratory symptoms like cough, shortness of breath, and chest tightness were significantly high in biomass fuel users than users of fossil fuel [26].

A number of co-factors were explored in this study which showed a significant role in the relationship between biomass fuel uses and respiratory symptoms. The young children aged between 6 and 23 months were 1.29 times more likely to have respiratory symptoms than other children. This is possible because of the practice of keeping these babies with mothers at the time of cooking. This result was supported by the two articles published in Nigeria [18] and Zimbabwe [22]. Vinod Mishra [22] showed that children at age 6-11 months and 12-23 months were 2.24 times and 1.90 times more likely to develop ARI comparing 0-5 months of children respectively. In Nigeria Demographic Health Survey (NDHS) revealed that children of the same age group were 2.66 times and 2.85 times higher chance of developing ARI than 36-59 months of children sequentially [18]. Children who practiced handwashing had less chance of developing a respiratory infection. Almost $66 \%$ of children suffered from symptoms of ARI in Nigeria for the poor practice of handwashing [18]. A systematic review was conducted on handwashing and respiratory infection which showed handwashing reduced respiratory infection ranging from $6 \%$ to $44 \%$ with a pooled reduction of $24 \%$ [27]. Faecal contamination on hand is highly associated with gastrointestinal and respiratory symptoms within a household which is possible to control by using improve toilet facilities [28]. More than $50 \%$ of children under 5 years of age suffered from respiratory health-related diseases due to the unhygienic sanitation system in Ethiopia [29]. Complication at the time of delivery or pregnancy period plays an important role in child health and is a potential risk factor for respiratory symptoms of a child as well. According to our analysis, the prevalence of mother's birth complications among in-house biomass fuel users was $34 \%$, whereas these percentages were $31.4 \%$ and $30.6 \%$ for the non-biomass users and biomass used in a separate room/ outdoor. Previous studies have demonstrated the association between preterm birth and chronic respiratory diseases [30]. Preterm infants with bronchopulmonary dysplasia and obstructive lung disease continued to suffer from the disease in adulthood and also were prone to develop the chronic obstructive pulmonary diseases [30]. The pooling of data from 14 European birth cohorts revealed a significant association between preeclampsia and recurrent wheezing among infants up to 2 years of age [31]. Birth order had a positive role in reducing respiratory symptoms. The first child of parents was more vulnerable to this problem and the rate of presence of respiratory symptoms was decreased as birth order increased. This is sometimes possible if the elder child takes care of his/her siblings at the time of the mother's cooking or working in the kitchen. But this result was opposite to the previous study as they found an increasing prevalence of ARI within higher birth order [18, 22]. Malnutrition is an important risk factor of developing ARI [32] which is also a leading cause of mortality and morbidity among children under 5 years of age [33]. Children of mothers having NGO membership were more vulnerable to respiratory symptoms. This reflects their socioeconomic status because poverty-stricken mothers usually take support from NGOs [34]. Our study findings showed that respiratory symptoms were high among children whose mother's education level was high. This result is very similar to the findings of a study from Nigeria [18] and a pilot study from Indonesia [35]. The educated mothers are more likely to be employed and usually keep their child alone or in the care of someone whose lifestyle may influence or exacerbate the respiratory symptoms.

In this study, we found that gender has no impact on respiratory symptoms which is similar to the other study findings $[18,22]$. Place of residence played a positive role in different studies, but an insignificant association with respiratory symptoms was observed in the final model though it showed significant association in bivariate analysis. It indicates that living in urban slums, non-slum or 
rest of the urban areas has no influence on the respiratory symptoms of children in Bangladesh.

Four models were used, in this analysis, to adjust the potential confounders. Sequential modelling helps to disentangle the dynamics of interplay occurring between each of the environmental and socio-demographic factors [18]. A similar strategy was also used in articles published in Zimbabwe [22] and Nigeria [18]. This study is not beyond the limitations. For lack of awareness or knowledge on respiratory symptoms, there is a possibility of underreporting or recall bias among the mothers using biomass during the 2 weeks of this study. Data were collected from self-reported measures on residential factors, mother characteristics, and child characteristics with respiratory symptoms. This may lead to results influenced by endogeneity problems. As this analysis was conducted using data obtained from a cross-sectional study, it is not possible to establish a causal relationship. Though tobacco smoking of parents is a well-known risk factor for respiratory symptoms in children [36], in this study this covariate has not been considered as this information is not available in UHS, 2013. The response variable respiratory symptoms of a child were not validated by a medical examination. Symptoms that are easily recognized by the mother namely cough or fast breathing or shortness of breathing were considered to define the response variable. Seasonality was not considered in this analysis due to the unavailability of data. One prior study found that the mean concentration of dust particles and volatile organic components (VOCs) such as benzene, toluene, and xylene were higher in winter season than summer in urban Dhaka [13]. The trend of emergency department visits at a hospital for asthma also gives the indicator of seasonality. A study conducted in Japan showed that the number of patients visited in the emergency department ranged from 1 to 15 per week and the high number occurred in autumn and spring months, mainly in September, October, and April [37]. The national-level DHS surveys collected data by the month of interview as a proxy seasonal factor and it shows no significant influence on the findings with or without this season factor [38].

\section{Conclusion}

This study found the use of in-house biomass fuel in the kitchen as a significant risk factor associated with respiratory symptoms in children under 5 years of age in urban Bangladesh. Apart from the mother's educational level and birth complications, other factors like toilet facility, exposure to NGO members, age of the children, birth order, and nutritional status of the child play a significant role in influencing respiratory symptoms. More longitudinal studies should be designed to establish a causal relationship between HAP and respiratory symptoms among children with other possible non-cooking sources of HAP, more direct measures of HAP and clinical procedure.

\section{Supplementary information}

Supplementary information accompanies this paper at https://doi.org/10. 1186/s12199-019-0827-3.

Additional file 1. Definition of different co-factor variables used in this article.

\section{Abbreviations}

WHO: World Health Organization; UNICEF: United Nations International Children's Emergency Fund; BUHS: Bangladesh Urban Health Survey; HAP: Household air pollution; LMIC: Low- and middle-income countries; ARTI: Acute respiratory tract infection; ARI: Acute respiratory infection; NGO: Non-government organization; VOCs: Volatile organic compounds

\section{Acknowledgements}

We thank MEASURE Evaluation and NIPORT for opening this data file in public. The authors would like to thank the Editor and reviewers for their useful comments and suggestions for the improvements in the quality of this paper.

\section{Authors' contributions}

$\mathrm{MH}$ and WB developed the study concepts and finalized the data analysis. $\mathrm{MH}$ wrote the first draft of this manuscript with the substantial input from all co-authors. ST, SMRH, KMSUR, MK, and SSI critically reviewed the manuscript. All authors read and approved the final manuscript.

Funding

There is no funding source for this study.

Availability of data and materials

Data for this study are available through the MEASURE Evaluation Data verse website (https://goo.gl/TixL9h).

\section{Ethics approval and consent to participate}

All participants gave informed consent before taking part in the survey. Additional approval was not necessary as the datasets are available in the public domain in anonymized form.

\section{Consent for publication}

Not applicable

\section{Competing interests}

The authors declare that they have no competing interests.

\section{Author details}

${ }^{1}$ Department of Public Health and Informatics, Bangabandhu Sheikh Mujib Medical University, Dhaka, Bangladesh. ${ }^{2}$ School of Public Health, Independent University, Dhaka, Bangladesh. ${ }^{3}$ Health Systems and Population Studies Division, icddr,b, Dhaka, Bangladesh. ${ }^{4}$ Department of Statistics, University of Dhaka, Dhaka, Bangladesh. ${ }^{5}$ Department of Public Health and Health Systems, University of Nagoya, Nagoya, Japan.

Received: 16 May 2019 Accepted: 6 November 2019

Published online: 27 November 2019

\section{References}

1. Fuels for Life: Household Energy and Health, Rehfuees E, WHO library cataloguing-in-publication data.; 2006.

2. Rehfuess E, Mehta S, Prüss-Üstün A. Assessing household solid fuel use: multiple implications for the millennium development goals. Environmental Health Perspectives. 2006;114(3):373-8.

3. The World Energy Assessment is a joint publication of UNDP, the UN Department for Economic \& Social Affairs and the World Energy Council.; 2004.

4. Household air pollution - the world's leading environmental health risk. World Health Organization (WHO); 2018.

5. Smith MADSMKR. Indoor smoke from solid fuels: assessing the environmental burden of disease at national and local levels. World Health Organization (WHO); 2004. 
6. Make every mother and child count. Geneva, Switzerland: World Health Organization (WHO); 2005.

7. Khan MN, CZ BN, Mofizul Islam M, Islam MR, Rahman MM. Household air pollution from cooking and risk of adverse health and birth outcomes in Bangladesh: a nationwide population-based study. Environmental Health. 2017;16(1):57.

8. Naz S, Page A, Agho KE. Household air pollution and under-five mortality in India (1992-2006). Environmental Health. 2016;15:54

9. Huda ASN, Mekhilef S, Ahsan A. Biomass energy in Bangladesh: current status and prospects. Renewable and Sustainable Energy Reviews. 2014; 30:504-17.

10. Baqui AH, Black RE, Arifeen SE, Hill K, Mitra SN. al Sabir A. Causes of childhood deaths in Bangladesh: results of a nationwide verbal autopsy study. Bulletin of the World Health Organization. 1998;76(2):161-71.

11. The Urbanization Prospects: The 2014 revision. United Nations; Department of Economic and Social Affairs; Population Division (2014), CD-ROM editor, File 20 (Annual Rural Population at mid year by major area, region and country, 1950-2050) and file 19 (Annual Urban Population at mid year by major area, region and country, 1950-2050); 2014.

12. Bangladesh Urban Health Survey. National Institute of Population Research and Training (NIPORT), Measure Evaluation, University of North Carolina at Chapel Hill, USA, and icddr,b.; 2013.

13. Khalequzzaman M, Kamijima M, Sakai K, Ebara T, Hoque BA, Nakajima T. Indoor air pollution and health of children in biomass fuel-using households of Bangladesh: comparison between urban and rural areas. Environmental health and preventive medicine. 2011;16(6):375-83.

14. ARl: Programme Review for Control of Acute Respiratory Infections. Sixth Programme Report:: World Health Organization: Geneva; 1993.

15. MC; C, LP; N, ED L. Rural mothers' management of acute respiratory infections (ARI) in region 10. 1993.

16. National Family Health Survey (NFHS-3), India: International Institute for Population Sciences (IIPS) and Macro International.; 2005-06.

17. Akunne AF, Louis VR, Sanon M, Sauerborn R. Biomass solid fuel and acute respiratory infections: the ventilation factor. International journal of hygiene and environmental health. 2006;209(5):445-50

18. Adesanya OA, Chiao C. A multilevel analysis of lifestyle variations in symptoms of acute respiratory infection among young children under five in Nigeria. BMC public health. 2016;16(1):880.

19. Upadhyay AK, Singh A, Kumar K, Singh A. Impact of indoor air pollution from the use of solid fuels on the incidence of life threatening respiratory illnesses in children in India. BMC Public Health. 2015;15(1):300.

20. World Health O. United Nations Children's Fund. Core questions on drinking water and sanitation for household surveys. Geneva: World Health Organization; 2006.

21. Blössner MOM. Global database on child growth and malnutrition. Geneva: World Health Organization; 1997.

22. Mishra V. Indoor air pollution from biomass combustion and acute respiratory illness in preschool age children in Zimbabwe. International journal of epidemiology. 2003;32(5):847-53.

23. Hosmer Jr DW LS, Sturdivant RX. Applied logistic regression. 3rd Edition ed: John Wiley \& Sons; 2013. 528 p.

24. Rawal LB, Kanda K, Mahumud RA, Joshi D, Mehata S, Shrestha N, et al. Prevalence of underweight, overweight and obesity and their associated risk factors in Nepalese adults: data from a Nationwide Survey, 2016. PloS one. 2018;13(11):e0205912-e.

25. Acharya P, Mishra S, Berg-Beckhoff G. Solid fuel in kitchen and acute respiratory tract infection among under five children: evidence from Nepal demographic and health survey 2011; 2014.

26. Khalequzzaman M, Kamijima M, Sakai K, Chowdhury NA, Hamajima N, Nakajima T. Indoor air pollution and its impact on children under five years old in Bangladesh. Indoor air. 2007;17(4):297-304.

27. Rabie T, Curtis V. Handwashing and risk of respiratory infections: a quantitative systematic review. Tropical medicine \& international health: TM \& IH. 2006;11(3):258-67.

28. Pickering AJ, Davis J, Walters SP, Horak HM, Keymer DP, Mushi D, et al. Hands, water, and health: fecal contamination in Tanzanian communities with improved, non-networked water supplies. Environmental science \& technology. 2010;44(9):3267-72

29. Gizaw Z, Biks GA, Yitayal M, Alemayehu GA, Alemu K, Awoke T, et al. Sanitation predictors of childhood morbidities in Ethiopia: evidence from
Dabat Health and Demographic Surveillance System. Environmental health and preventive medicine. 2019;24(1):43.

30. Kwinta P, Pietrzyk JJ. Preterm birth and respiratory disease in later life. Expert Review of Respiratory Medicine. 2010:4(5):593-604.

31. Zugna D, Galassi C, Annesi-Maesano I, Baiz N, Barros H, Basterrechea M, et al. Maternal complications in pregnancy and wheezing in early childhood: a pooled analysis of 14 birth cohorts. International journal of epidemiology. 2015;44(1):199-208.

32. Cunha AL. Relationship between acute respiratory infection and malnutrition in children under 5 years of age. Acta paediatrica (Oslo, Norway : 1992). 2000;89(5):608-9.

33. Chalabi DA. Acute respiratory infection and malnutrition among children below 5 years of age in Erbil governorate, Iraq. Eastern Mediterranean health journal $=$ La revue de sante de la Mediterranee orientale $=$ alMajallah al-sihhiyah li-sharq al-mutawassit. 2013:19(1):66-70.

34. Khan H, T. Rahman M, Kabir M. Women's participation in economic activities in Bangladesh2014.

35. Shibata T, Wilson JL, Watson LM, LeDuc A, Meng C. Ansariadi, et al. Childhood acute respiratory infections and household environment in an Eastern Indonesian urban setting. International journal of environmental research and public health. 2014;11(12):12190-203.

36. Li JS, Peat JK, Xuan W, Berry G. Meta-analysis on the association between environmental tobacco smoke (ETS) exposure and the prevalence of lower respiratory tract infection in early childhood. Pediatric pulmonology. 1999; 27(1):5-13.

37. Khan MS, Coulibaly S, Matsumoto T, Yano Y, Miura M, Nagasaka Y, et al. Association of airborne particles, protein, and endotoxin with emergency department visits for asthma in Kyoto, Japan. Environmental health and preventive medicine. 2018;23(1):41

38. Chiao C. Community vulnerability and symptoms of acute respiratory infection among preschool age children in the Democratic Republic of Congo, Malawi and Nigeria: evidence from Demographic and Health Surveys. Journal of epidemiology and community health. 2017;71(1):81-6.

\section{Publisher's Note}

Springer Nature remains neutral with regard to jurisdictional claims in published maps and institutional affiliations.
Ready to submit your research? Choose BMC and benefit from:

- fast, convenient online submission

- thorough peer review by experienced researchers in your field

- rapid publication on acceptance

- support for research data, including large and complex data types

- gold Open Access which fosters wider collaboration and increased citations

- maximum visibility for your research: over $100 \mathrm{M}$ website views per year

At $\mathrm{BMC}$, research is always in progress.

Learn more biomedcentral.com/submissions 